\title{
El lugar político de la justicia y la verdad en la justicia transicional en Colombia*
}

\author{
Francisco Cortés Rodas (Colombia)**
}

\section{Resumen}

El autor hace una lectura contextual del concepto de justicia transicional para enfatizar en la discusión sobre elementos como el perdón y la responsabilidad, y para articular de mejor forma los fenómenos legales y morales que han sido tratados de manera unilateral en recientes procesos transicionales. Es importante destacar lo problemático que resultaría el proceso de justicia transicional en Colombia si no se equilibran las dimensiones jurídicas y políticas con la dimensión moral. La dimensión jurídica es fundamental y debe haber un castigo para los responsables de graves crímenes, pero es necesario adoptar una visión no retributiva del castigo. Para desarrollar los elementos de esta controversia se plantea si en las condiciones de la negociación política en Colombia es posible la aplicación de la justicia penal en un sentido normal. En la parte final se analiza la afirmación de los opositores del proceso de paz de que este no constituye más que una política de impunidad. Esto se hace mediante la reconstrucción del Marco Jurídico para la Paz y del Acuerdo sobre las Víctimas del Conflicto.

\section{Palabras clave}

Justicia Transicional; Justicia Retributiva; Proceso de Paz; Colombia.

Fecha de recepción: junio de 2016

- $\quad$ Fecha de aprobación: noviembrede 2016

\section{Cómo citar este artículo}

Cortés Rodas, Francisco. (2017). El lugar político de la justicia y la verdad en la justicia transicional en Colombia. Estudios Políticos (Universidad de Antioquia), 50, pp. 216-235. DOI: 10.17533/udea.espo.n50a12

\footnotetext{
* Este artículo hace parte del proyecto de investigación del periodo 2014-2015, Repensar la Democracia: Reflexiones en torno a los criterios de legitimación del poder politico en el contexto de un mundo globalizado, aprobado por el Comité para el Desarrollo de la Investigación (CODI) de la Universidad de Antioquia.

** Filósofo. Magíster y doctor en Filosofía. Director del Instituto de Filosofía, Universidad de Antioquia UdeA. Calle 70 No. 52-21, Medellín, Colombia. Correo electrónico: francisco.cortes@ udea.edu.co
} 


\title{
The Political Place of Justice and Truth in Transitional Justice in Colombia
}

\begin{abstract}
The author provides a contextual reading of the concept of transitional justice, with the purpose of emphasizing on other elements in the discussion as forgiveness and responsibility, and to better articulate the legal and moral phenomenon that have been discussed unilaterally in recent transitional processes. It is important to highlight how problematic Colombia's transitional justice process would result if the juridical and political dimensions were not balanced with the moral dimension. The juridical dimension is fundamental and there must be a punishment for those who are responsible of serious crimes, but it is necessary to adopt a non-retributive vision of punishment. To develop the elements of this controversy, the question posed is: in the conditions of the political negotiation in Colombia, is the application of regular penal justice possible? In the last part, there will be an analysis on the claims made by the opposition, according to which said process constitutes nothing more than a policy of impunity. This is done through the reconstruction of the Legal Framework for Peace and the Agreement on the Conflict's Victims.
\end{abstract}

\section{Keywords}

Transitional Justice; Retributive Justice; Peace Process; Colombia. 


\section{Introducción}

Un elemento importante de la negociación del Gobierno de Colombia con las Fuerzas Armadas Revolucionarias de Colombia (FARC) debe consistir en la inclusión de procesos de reconocimiento público de atrocidades políticas y de violaciones de los derechos humanos. Esta forma de reconocimiento es de relevancia, precisamente, porque constituye una manera de redescubrir el significado y el valor de las personas como ciudadanos y como víctimas. Para una sociedad en transición constituye una prioridad política insistir en este tipo de procesos de aseguramiento de la justicia, develamiento de la verdad, perdón, reconocimiento de las víctimas y garantías de no uso de las armas y la violencia contra la sociedad.

El acuerdo conseguido en La Habana entre los representantes del Gobierno y las FARC, renegociado tras el triunfo del No en el plebiscito del 2 de octubre de 2016, suscrito por las partes en Bogotá el 24 de noviembre de 2016 como el Nuevo Acuerdo Final (NAF), y refrendado en el Congreso, permite afirmar que la justicia transicional, con sus componentes de verdad, justicia, reparación y garantías de no repetición, está adquiriendo en Colombia una base sólida. Su consecución indica que con el fin de las negociaciones se sientan las bases para un nuevo comienzo: la paz.

Hugo Grocio (1925) afirma que la paz exige un cierto sacrificio de la justicia. En un sentido similar, Emerich de Vattel (1916) plantea la idea de una justicia compensatoria al lado de la justicia retributiva. De otro lado, Thomas Hobbes (1994) afirma que es necesario superar el retributivismo en el derecho penal porque si se sostiene una equivalencia entre el mal causado y el mal que se causa con la pena se ocasionará la guerra y la sociedad volverá al estado de naturaleza.

¿Qué es lo que quieren decir estos autores sobre aquellas situaciones en las que para conseguir la paz en un determinado Estado se requiere limitar las exigencias de la justicia? Para esto se debe precisar, primero, ¿qué se entiende aquí por justicia? La respuesta no es tan sencilla, porque más allá de una intuición de fondo universalmente compartida de la justicia como un fundamento estructural de la sociedad, hay una fuerte controversia que se ha radicalizado en los últimos años, especialmente en países que viven procesos políticos transicionales, sobre si la justicia debe o no tener un valor prioritario frente a las exigencias políticas de la paz (Crocker, 2000). En este 
sentido, uno de los problemas que aquí se abordarán es si en Colombia es posible reaccionar frente a una criminalidad masiva con una persecución penal masiva e individualizada, si en las actuales condiciones la justicia penal plena es posible.

Para desarrollar los elementos de esta controversia planteará en un plano filosófico qué significa: la paz exige un cierto sacrificio de la justicia. Esto conduce a analizar si en las condiciones de la negociación política en Colombia es posible la justicia penal plena. Para esto se expondrá la cuestión acerca de la justificación del derecho penal en un Estado de derecho y cuál es su función y propósito general, para contrastarla con los problemas que resultan en sociedades que salen de una guerra o de una dictadura. Finalmente, se analizará la afirmación crítica hecha por los opositores del proceso de paz en Colombia, según la cual este no constituye más que una política de impunidad. ${ }^{1}$ A partir de una reconstrucción del Marco Jurídico para la Paz (MJP) y del Acuerdo sobre las Víctimas del Conflicto (AVC), buscaré dar las razones para mostrar que el propósito de alcanzar la paz en Colombia no producirá como consecuencia que los graves crímenes cometidos por los miembros de las FARC queden impunes.

Cada una de estas perspectivas está basada tanto en una tradición teórica honorable como en una práctica política valiosa, pero lo interesante del estudio metódico que aquí se propone es el intento de relacionar de forma sistemática la necesidad imperativa de la justicia con la necesidad política de la paz.

\section{Justicia y paz}

En la formación de los modernos Estados europeos, después del fin de las guerras religiosas y de la paz de Westfalia, todos aquellos que escribieron sobre el problema de la guerra estuvieron de acuerdo en que el fin de una guerra es conseguir una paz justa y duradera. Para Hobbes (1994) el estado de naturaleza es la situación de guerra de todos contra todos, situación en la que no hay manera de establecer ni la propiedad, ni la sociedad. En esta situación predominaba un mundo sin ley, la anarquía. En el estado de naturaleza los

\footnotetext{
${ }^{1}$ Los más importantes opositores de las negociaciones del Gobierno con las guerrillas son: José Miguel Vivanco, vocero de Human Rights Watch (HRW), la ONG Amnistía Internacional, el expresidente Álvaro Uribe Vélez, el partido Centro Democrático, el ex procurador general de la Nación Alejandro Ordoñez, entre otros.
} 
hombres son iguales porque tienen el mismo poder, es decir, el poder de someter al otro y, si se opone, de asesinarlo, «porque en lo que toca a la fuerza corporal, aún el más débil tiene fuerza suficiente para matar al más fuerte» ( $p$. 100). Esta condición de igualdad, en la cual todos son potenciales asesinos, pone a los hombres en una situación de igual inseguridad y, por tanto, de un miedo recíproco frente a la posibilidad de una muerte violenta (Biral, 2002, p. 78).

Los hombres pueden salir de ese estado de guerra, dice el autor de $E I$ Leviatán, debido a sus pasiones y a su razón. Las pasiones que inclinan a los hombres a la paz son el temor a la muerte, el deseo de las cosas que son necesarias para una vida confortable y la esperanza de obtenerlas por medio del trabajo. La razón sugiere adecuadas normas de paz, a las cuales pueden llegar los hombres por mutuo consenso. El Leviatán de Hobbes cumple con esa tarea instaurando un poder legítimo (Hobbes, 1994).

Kant (1986) consideró que la guerra es un mal intolerable y que es necesario que los Estados tomen medidas encaminadas a poner fin a su utilización con el fin de poder asegurar los derechos de sus ciudadanos. Para Kant, la función del contrato social no es la de establecer un soberano para que [220] asegure y proteja los derechos de cada uno, como en Hobbes, sino más bien, definir las condiciones de una socialización bajo el dominio del principio del derecho. Por medio de este se determinan los requisitos bajo los cuales los derechos adquieren una validez legítima. Pues, «el derecho es la limitación de la libertad de cada uno a la condición de su concordancia con la libertad de todos, en tanto que esta concordancia sea posible según una ley universal» (p. 26).

Kant (1989) piensa el problema de la guerra en función de crear las condiciones para que el mundo de la experiencia de los hombres dominado por la guerra se pueda convertir en un mundo de la humanidad ordenado por el derecho. Del contrato entre los ciudadanos surge el Estado, del contrato entre Estados emerge la federación de Estados, basada en el nuevo derecho internacional, orientado hacia la paz. El derecho internacional que Kant formula no reconoce a la guerra como un proceso jurídico. Afirma que es un error considerar toda guerra como justa, pues la guerra en sí es contraria al derecho. Propone, en cambio, la paz como deber estricto entre los hombres. De este modo, el fundamento del Estado liberal moderno lo constituye el individuo y su inalienable dignidad humana en el sentido del reconocimiento 
que propone Kant, que se basa en el respeto a la libertad de cada miembro de la sociedad, en cuanto hombre, y en los valores de autonomía, igualdad, dignidad humana e independencia. En este sentido, la dignidad humana debe ser el punto fijo $\mathrm{y}$, al mismo tiempo, el de partida de todo el sistema del derecho: el constitucional, el civil y el penal.

En la filosofía política moderna se establece una relación sistemática entre la soberanía, la justicia y la paz. La justicia solamente es posible bajo la condición de la soberanía estatal. Este argumento es originalmente de Hobbes (1994) y lo siguieron Kant (1989), Weber, (2002), Rawls (1978) y Habermas (1998), con importantes variaciones. La justicia es entendida como una propiedad de las relaciones entre los seres humanos que para realizarse requiere de la existencia de la soberanía, lo que supone también que debe haber una sociedad pacificada. Para decirlo en forma negativa, sin soberanía como condición que hace posible la realidad del Estado, la justicia y la pacificación de las relaciones sociales serían una pura utopía.

La base de legitimación es que el Estado ejercite fuerza, de un lado, y produzca un orden social justo, del otro. Para ser preciso, un Estado puede ser considerado legítimo si realiza la justicia, esto es, el Estado requiere de un marco social impuesto colectivamente, promulgado en nombre de todos aquellos gobernados por él y aspirando exigir la aceptación de su autoridad por todos los asociados.

El modelo liberal de soberanía que emergió después de la Segunda Guerra Mundial afirma como idea central que es posible regular las relaciones entre los Estados, no a partir de la soberanía y la guerra, sino de la garantía de los derechos humanos individuales. En el núcleo del liberalismo universalista está la tesis que afirma que cada hombre tiene el mismo valor o el mismo derecho a la libertad y a la autonomía, y que esta circunstancia lleva consigo obligaciones morales y responsabilidades que tienen alcance universal y que obligan a los Estados.

En el liberalismo, basado en la dignidad humana, se afirma que la igualdad es la base de nuestra moral política y a partir de esto se determina qué tipo de instituciones se deben construir para realizar la justicia. Para establecer cuáles son estas instituciones y cómo deben ser distribuidos los bienes y las responsabilidades, se diferencian cuatro esferas de la justicia, a saber: la política, la penal, la económica y la social. 


\section{El castigo justo}

En este punto es pertinente la pregunta fundamental acerca de la justificación del derecho penal en un Estado de derecho y cuál es su función y propósito general. Se puede afirmar primero que en un Estado democrático de derecho, las normas penales deben perseguir solamente como objetivo asegurar a los ciudadanos una coexistencia pacífica y libre bajo la garantía de los derechos humanos. El Estado debe entonces garantizar, mediante el sistema de coacción - que comprende entre otros al derecho penal-, la protección de la vida, la libertad de movimiento, de opinión y pensamiento, la salud, la propiedad, entre otros. En este sentido:

En un Estado liberal de derecho, el derecho penal en general sirve a un propósito particular: se supone que debe garantizar la convivencia pacífica de los seres humanos en la comunidad. Se discute, sin embargo, qué es lo que exactamente protege el derecho penal para lograr este propósito: ¿bienes jurídicos?, ¿intereses?, ¿normas? ¿O la ley penal sirve/debería servir a la prevención del daño? (Ambos, 2013, p. 61).

Las dos justificaciones principales — protección de bienes jurídicos y la prevención del daño— se examinarán en este apartado.

Para el análisis de la justicia penal se parte de la distinción clásica introducida por Grocio (1925) entre teorías absolutas que retribuyen — punitur, quia peccatum est- y teorías relativas orientadas preventivamente - punitur, ne peccetur-. La doctrina retributiva declara que si una persona debe ser castigada, esto debe decidirse por referencia solamente a las ofensas legales cometidas por ella: «La naturaleza permite imponer un mal a aquél que ha cometido un mal» (p. 97). Por su parte, Samuel Pufendorf (2002) afirma que «el auténtico fin de las penas humanas es la prevención de agresiones y afrentas que se produce si se enmienda el que ha cometido delito o bien otros con su ejemplo. [...] La pena tiene que ser de tal naturaleza que la infracción de la ley acarree, de modo visible para todos, un mal mayor que su seguimiento» (p. 146).

La doctrina retributiva contiene dos demandas: que solamente las personas que hayan cometido crímenes deben ser castigadas y que los castigos deben ser proporcionales al tipo de crimen cometido, de tal manera que los más serios crímenes reciben los más severos castigos y los menos serios 
reciben los castigos menos severos. Se expondrán algunos argumentos de Kant y Hegel por ser dos de los autores más representativos del retributivismo de la Modernidad.

Kant (1989) justifica la existencia del Estado como un sistema legal en función de la protección de la libertad. Cualquier violación de la libertad individual es injusta o contraria al derecho y la coerción que previene la violación de la libertad individual está justificada en su sistema. El castigo limita en un grado importante la libertad del ofensor. Tal limitación de la libertad del ofensor es aceptable porque asegura no volver al estado de naturaleza. De este modo, debido a que un sistema de castigo es parte integral del sistema legal, la justificación del Estado implica, por tanto, un sistema de castigo, al menos en la medida en que el castigo promueve ese fin que legitima al Estado (p. 40).

De esto se deriva lo siguiente: de un lado, Kant (1989) considera que mientras que un sistema legal tiene poderes de imposición coercitiva en términos de asegurar la libertad individual, ningún individuo debe ser utilizado como un simple medio para obtener ese resultado. Esto quiere decir que el fin del castigo no es destruir la libertad de elección del criminal, sino la de persuadirlo para usar su libertad de una forma consistente con la libertad de los otros. Así, cualquier castigo que pueda dañar la autonomía del criminal es excluida por esta teoría. Para Kant, una vez que se ha encontrado al delincuente merecedor de un castigo, debe ser castigado sin tomar en consideración ponderaciones de prudencia, pues «la ley penal es un imperativo categórico» (p. 166).

El desarrollo del lado social del delito se halla en el centro de la teoría de la pena de Hegel (1993), quien afirma en su Filosofía del derecho que el castigo es el restablecimiento del derecho, en la medida en que el derecho niega, a la vez, la negación del derecho que representa el delito. El crimen es una coerción injustificada porque viola el derecho a la libertad. El castigo es una segunda coerción dirigida contra la primera, es una coerción de la coerción. Como tal, el castigo es una coerción justificada. Para Hegel, el castigo es no solo el derecho del Estado para desarrollar y legitimar la ley, sino también el derecho del transgresor, no solo de ser castigado, sino también de ser reconocido como un ser humano. «La vulneración que afecta al delincuente no sólo es justa en sí, sino que es también un derecho afirmado en el delincuente mismo, esto es, en su voluntad existente, en su acción» (Hegel, 1993, § 100). 
Hegel aplica su teoría del reconocimiento al castigo y de este modo cualifica la retribución. Así, al entender el castigo como una forma de reconocimiento recíproco, la retribución no es el «ojo por ojo» de la ley del talión, de la venganza, sino una reciprocidad duradera que reconoce al ser humano como un ser sujeto de derechos. La venganza, cuando se trata de castigar por el gusto de castigar, no es tenida en cuenta por Hegel como uno de los fines legitimadores del castigo debido a que se opone a la naturaleza del ser humano deleitarse con el dolor ajeno.

El retributivismo busca desarrollar justificaciones del derecho penal en un Estado de derecho. Así pregunta: ¿cuál es la función y propósito del derecho penal? Para presentar su respuesta señala que la contradicción del delito debe producirse por medio de la coacción, infligiendo dolor por medio de la restricción de la libertad:

El dolor sirve para la salvaguardia cognitiva de la violencia de la norma; este es el fin de la pena. [...] El autor ha determinado y ejecutado su conducta sin consideración de la vigencia del Derecho. En la medida en que ello implique la afirmación de que la norma no le vincula, se le contradice a través de la pena el significado de la pena (Jakobs, 2007, pos. 586).

En suma, el que comete un crimen no debe ser denominado simplemente como un delincuente, sino que debe, además, ser tratado como un criminal y excluido por un tiempo prudencial de la comunicación con los otros hombres, de acuerdo con la gravedad del injusto cometido.

Si al autor se le inflige un dolor penal de tal intensidad que a causa del dolor su hecho es generalmente considerado un fracaso, con ello queda claro que en el futuro, el apoyo cognitivo de la norma al menos no será peor que antes del hecho; este mantenimiento del lado cognitivo de la vigencia de la norma es el fin de la pena, y en función de tal fin ha de determinarse la pena (Jakobs, 2007, pos. 586).

De esta forma, la violación del derecho a la libertad que introduce el autor del delito se restablece con el tratamiento como delincuente, y así mantiene el derecho su fuerza de orientación, su vigencia.

Hobbes es uno de los representantes de las teorías relativas del castigo, posteriormente denominadas utilitaristas, que se orientan no al pasado, sino 
al futuro - punitur, ne peccetur-, es decir, plantean que se debe castigar no por el crimen ya cometido, sino para que aquel que lo cometió no se atreva a repetir, ni tampoco lo hagan los otros que evidencian el castigo. Hobbes critica el retributivismo porque en este se establece una relación directa entre la venganza y el castigo. Para el retributivismo, la justicia supuesta en la pena consiste en que el que ha infligido un mal debe sufrir un mal. Esto es venganza. De acuerdo con Hobbes (1994): «En la venganza -la retribución de un mal mediante otro mal — no se debe observar la magnitud del mal ocasionado sino la utilidad de cara al futuro. De aquí se deriva la prohibición de castigar con otra intención que no sea la mejora del autor o la dirección de otras personas» (p. 254 ss).

Para el autor de El Leviatán, si la venganza es permitida ocasionará la guerra y la sociedad volverá al estado de naturaleza, empeorándose así las oportunidades del individuo. El castigo debe servir para mejorar al autor y para que los otros miembros de la sociedad vean en el ejemplo del castigado que cometer delitos ocasiona sanciones.

En este sentido, mientras que para la teoría retributiva las consecuencias del castigo son irrelevantes y lo que importa es la ejecución de lo ordenado por los tribunales, para las teorías relativas, denominadas también utilitaristas, lo relevante son, precisamente, las consecuencias (Primoratz, 1989, 18). En el marco de la filosofía política moderna estos argumentos sobre la justicia, la paz y el castigo tienen hoy una importante influencia, incluso en la literatura sobre justicia transicional.

Se afirmó al inicio de este apartado que la función de la coacción en un Estado liberal de derecho debe ser garantizar la convivencia pacífica de los seres humanos en la comunidad. Expuestos los argumentos básicos de las dos justificaciones principales del sistema coactivo del Estado, la teoría retributiva y la teoría de la prevención del daño, se planteará a continuación la tensión que enfrenta el sistema penal retributivo en sociedades que están saliendo de la guerra o de un régimen dictatorial.

\section{La relativización del castigo}

En la perspectiva de la justicia restaurativa se afirma, de un lado, que en un proceso transicional el sufrimiento de las víctimas debe ser reconocido mediante una vía distinta a la retributiva; de otro lado, que los perpetradores 
deben ser hechos responsables frente a las exigencias de verdad y reparación de las víctimas; además, que los transgresores deben realmente arrepentirse y buscar así el perdón de sus víctimas; finalmente, que la justicia no requiere necesariamente la implementación de medidas punitivas, pues con un mecanismo como la comisión de la verdad es posible que los ciudadanos, apelando a sus propias tradiciones culturales, logren la justicia, la verdad y la reparación. El esclarecimiento de la verdad y el establecimiento de hechos históricos podrían alcanzarse con independencia de un proceso penal e incluso con mayor eficacia que en este.

Con la utilización de este enfoque alternativo a la justicia retributiva se trata fundamentalmente de que no se llegue a permitir una amnistía total o general para los criminales. Esto es especialmente importante en sociedades que están saliendo de la guerra o de la dictadura, donde hay una ausencia de condiciones fácticas y jurídicas para procesar y juzgar a los responsables en un proceso justo.

En un Estado democrático de derecho, enjuiciar a criminales reafirma el principio de que nadie está más allá del alcance de la ley y que los ciudadanos tienen derechos. Los juicios a los violadores de derechos humanos reafirman

[226] la autoridad de las instituciones democráticas y ayuda a que los miembros de la comunidad recuperen el sentido del respeto que habían perdido. El castigo se vincula con la consolidación de instituciones de autoridad democrática, especialmente las judiciales. Este es el caso en las sociedades democráticas normales.

Pero el problema en sociedades que están saliendo de la guerra o de un régimen dictatorial, es que estas ventajas de las medidas retributivas pueden no darse por los inconvenientes de llevar a cabo juicios penales contradictorios a los violadores de derechos humanos (Nino, 1996). Es claro que en estas sociedades no es posible investigar y castigar a todos los autores de grandes atrocidades. Ni en Núremberg ni en los tribunales ad hoc de la antigua Yugoslavia (ICTY) y de Ruanda (ICTR) se ha castigado a todos los posibles autores de violaciones de los derechos humanos, del derecho internacional humanitario o del derecho internacional penal. Ningún sistema judicial del mundo tiene la capacidad de perseguir todos los delitos y castigar a todos los culpables (Elster, 2006, p. 33). La posibilidad de reaccionar frente a una criminalidad masiva con una persecución penal masiva está excluida. En este caso, el Estado no puede cumplir con su obligación de juzgar y la norma pierde su carácter real. 
Si bien es cierto que el encarcelamiento separa por un tiempo al criminal de la sociedad, ni el retributivismo, ni el utilitarismo han dado razones convincentes para demostrar la relación sistemática entre crimen y castigo que justifique como única salida la prisión. Esta limitación es señalada por teóricos de la visión comunicativa del castigo como Antony Duff y Jean Hampton. ${ }^{2}$ Duff (2015) afirma que:

Una perspectiva comunicativa del castigo atribuye un lugar central a la participación del delincuente, al menos si describe al castigo como un proceso bidireccional de comunicación, de la comunidad política al delincuente y viceversa. Conforme a esta concepción lo que el tribunal dice al convicto al emitir la sentencia es que esta es lo que él debe tomar a su cargo como una expiación, una forma de reparación simbólica por lo que ha hecho; o el castigo constituye un ritual de disculpa que el delincuente debe llevar a cabo (pos. 671).

Hampton (2007) considera que «el castigo debe ser previsto como una vía para enseñarle al criminal que la acción que realizó es prohibida porque ella es moralmente mala, y no debe ser hecha por esta razón» (p.143). En este sentido, el uso del castigo debe orientarse a que el delincuente, por medio de la comunicación, adopte una actitud reflexiva sobre sus acciones indebidas, las reconozca como actos contrarios a la ley y al derecho de los demás, y se comprometan con acciones de reparación. Esta autora explica el castigo como un bien para aquellos que lo experimentan, "como algo hecho "para ellos", no "a ellos", algo planeado para realizar un fin que incluye su propio bienestar moral». Por su parte, Duff (2015) afirma que: «El encarcelamiento constituye y marca una exclusión de la vida cívica ordinaria. Sin embargo, puede imponerse y administrarse de manera tal que no sea meramente excluyente: como una suspensión temporaria y parcial de la asociación que busca su propio fin» (pos. 734). Así, estos autores niegan el fundamento del retributivismo a partir de las preguntas: ¿qué sociedad es la que permite que en su sistema penal domine la idea primitiva de la venganza? ¿Cómo puede considerarse moralmente apropiado causar un mal por otro mal que ha sido hecho?

Tenemos, entonces, dos formas de hacer justicia: reparar por los daños sufridos a través de contar la verdad e imponer castigos justos a los culpables, no venganzas (Elster, 2006; p. 317). Ahora bien, considerando estas razones

\footnotetext{
${ }^{2}$ Aquí solamente se señala brevemente esta perspectiva que se desarrollará en posteriores trabajos.
} 
teóricas y estos hechos políticos, se puede plantear una pregunta que será tratada más ampliamente en el próximo apartado: ¿qué significa que en la justicia transicional de Colombia esté definido en el MJP y en el AVC que los objetivos políticos del castigo no deben reducirse a penas de cárcel? y ¿qué significa que la perspectiva de la justicia no se oriente por el sistema de la responsabilidad criminal individual? Estas dos preguntas permiten avanzar en el objetivo de este artículo: considerar si es posible tratar el juzgamiento y condena de los responsables de crímenes atroces en el marco de una concepción alternativa de justicia en la cual se articule el proceso penal con el componente de verdad, tan importante en los procesos orientados por la justicia transicional.

\section{4. ¿El proceso de negociaciones del Gobierno con las FARC es la expresión de un pacto de impunidad?}

Es importante señalar que en este momento se da un giro de la teoría general a la situación colombiana. Para cuestionar la aseveración hecha por algunos críticos del proceso de paz, según la cual este no constituye más que una política de impunidad, se reconstruirá el MJP y solamente el Acuerdo de Víctimas del Conflicto del Acuerdo Final con el fin de exponer el conjunto de

[228 ] razones para fundamentar el argumento según el cual el propósito de alcanzar la paz no tiene como consecuencia que los graves crímenes cometidos por los miembros de las FARC quedarán impunes.

Los opositores al proceso de paz sostienen que lo que se está buscando en estas negociaciones es reformar la Constitución a fin de legalizar la capitulación ante las FARC. En este sentido, señalan que los conceptos desarrollados en el MJP como «sistema extrajudicial de justicia transicional», «mecanismos extrajudiciales», «selección y priorización» y «máximos responsables», y la nueva Jurisdicción Especial para la Paz (JEP) propuesta en el NAF son los instrumentos de una política que el Gobierno está impulsando para negociar la terminación del conflicto armado interno, sin reconocer la situación de las víctimas y las responsabilidades de las FARC frente a la violación de los derechos humanos. Aseveran por esto que el MJP y el NAF son claramente la expresión de un pacto para otorgar una amnistía absoluta a los miembros de las guerrillas. ¿Pero se puede decir que el Acto Legislativo 01 de 2012 (MJP) y el NAF son instrumentos de una política de impunidad?

La impunidad es un hecho frecuente que se ha dado de múltiples formas en todo el mundo. Significa, por ejemplo, que los ataques y violaciones de 
los derechos humanos contra la población civil en Argentina, Chile, Siria, Ucrania, Palestina y Colombia no han tenido consecuencias penales ni para los jefes de Estado, ni para los militares, ni para los paramilitares, ni para las guerrillas involucradas en masacres y graves crímenes. Significa también que las violaciones de los derechos humanos o delitos de lesa humanidad, encubiertos, iniciados o promovidos por el Estado en distintos países del mundo, quedan sin castigo. A continuación se analiza cada uno de estos instrumentos normativos desarrollados para adelantar las negociaciones con los grupos armados.

\subsection{Análisis del Marco Jurídico para la Paz}

El Gobierno propuso una estructura jurídica para la paz en la que se contempla una serie de condiciones para la negociación en el contexto de la justicia transicional, construidas en el marco de los parámetros de la justicia internacional penal y de los derechos humanos. ${ }^{3}$ El MJP introdujo en la Constitución los Artículos Transitorios 66 y 67, y con esto propuso los límites jurídicos conforme a los cuales se pueden realizar negociaciones para poner fin al conflicto armado colombiano. El mencionado marco normativo plantea que en situaciones de terminación de un conflicto armado, la mejor forma de enfrentar graves violaciones de los derechos humanos es mediante los mecanismos de justicia transicional, es decir, mediante la articulación de las exigencias de justicia con las de verdad, reparación y garantías de no repetición.

Por medio de esta reforma constitucional se establece cómo debe darse la investigación y judicialización de los integrantes de grupos armados organizados al margen de la ley en Colombia. Para realizar estos objetivos, «el proyecto determina que los instrumentos de justicia transicional tendrán como finalidad prevalente la terminación del conflicto armado interno y el logro de la paz estable y duradera, garantizando la seguridad de todos los colombianos» (Corte Constitucional, Sentencia C-579 de 2013, art. $1^{\circ}$ inc. $1^{\circ}$ ).

Para hacer efectiva la investigación de los procesos de justicia, la ley establece la posibilidad de clasificar y priorizar los distintos delitos para que la Rama Judicial se concentre en la investigación y sanción de quienes tuvieron

\footnotetext{
${ }^{3}$ De esta estructura normativa hacen parte las Leyes 782 de 2002 y 975 de 2005 y decretos reglamentarios con los que se vienen tratando los proceso de negociación con grupos armados organizados al margen de la ley.
} 
la mayor responsabilidad en la ocurrencia de los hechos más graves: «Se determinan así criterios de priorización y selección de casos para ser juzgados por medio de mecanismos judiciales o no judiciales. Se podrá ordenar además la renuncia a la persecución penal de los casos que no sean seleccionados o priorizados» (Corte Constitucional, Sentencia C-579 de 2013, art. $1^{\circ}$ inc. 4).

En suma, en el MJP el Gobierno planteó la idea de que solo algunos de los guerrilleros - los que han cometido los actos más atroces- deberán ser castigados, pues sería imposible investigar y sancionar a los aproximadamente seis mil combatientes que se reinserten (El Tiempo, 2016, septiembre 28). En la medida en que es imposible el enfoque de la investigación siguiendo una idea de exhaustividad o maximalización, la Corte Constitucional justifica que el MJP introduzca un cambio en la perspectiva sobre la base de una estrategia de selección y priorización.

\subsection{Análisis del Acuerdo sobre las Víctimas del Conflicto}

En primer lugar, el AVC está basado en el aseguramiento de la justicia e incluye para esto mecanismos judiciales que permiten la investigación y sanción de graves crímenes. En el modelo se plantea el proceso penal

[230] contradictorio, que quiere decir que las FARC serán judicializadas y que deben por tanto aceptar responsabilidad penal; se introduce también un mecanismo extrajudicial, la Comisión de la Verdad, que es una vieja demanda del movimiento de derechos humanos y de justicia transicional. Esto último es también un elemento muy útil, ya que permitirá que el elemento verdad en el actual proceso de justicia transicional no sea absorbido completamente por la verdad judicial, cuyo marco de referencia — que divide al mundo entre víctimas puras y victimarios puros- es demasiado estrecho para dar cuenta de un conflicto como el colombiano.

En concordancia con la diferenciación entre delitos políticos y los más graves crímenes, el AVC diferencia, de un lado los amnistiables, que son aquellas personas acusadas o condenadas por delitos políticos o conexos, que serán la mayoría de los guerrilleros. Ellos recibirán una amnistía lo más amplia posible, de conformidad con el Artículo 6 Inciso 5 del Protocolo adicional Il a los Convenios de Ginebra (CICR, 1977). En el acuerdo se propone que la determinación concreta de los delitos amnistiables se hará en una futura Ley de amnistía. Y de otro lado, están los no amnistiables, que son aquellas personas que cometieron crímenes de lesa humanidad, genocidio y crímenes de guerra. 
En el Nuevo Acuerdo Final, renegociado tras el triunfo del No en el plebiscito del 2 de octubre de 2016, suscrito por las partes en Bogotá el 24 de noviembre de 2016, se incluyeron precisiones en la determinación de las sanciones restaurativas. Los delitos no amnistiables serán investigados por el Tribunal para la Paz que los procesará e impondrá las sanciones que incluirán restricciones efectivas de la libertad o pena privativa de la libertad, dependiendo de si las personas en el proceso de investigación reconocen o no su responsabilidad. Para quienes reconozcan su responsabilidad ante la Sala de Reconocimiento de Responsabilidad habrá restricciones efectivas de la libertad de cinco a ocho años. Para quienes reconozcan de manera tardía su responsabilidad ante el Tribunal para la Paz habrá pena privativa de la libertad en condiciones de reclusión ordinarias de cinco a ocho años, esto se hará en unas zonas veredales, de las cuales no podrán salir los condenados. Para quienes no reconozcan su responsabilidad, y tras el juicio contradictorio, sean declarados culpables habrá pena privativa de la libertad en condiciones ordinarias de reclusión de quince a veinte años.

Es importante señalar que en todos los casos hay restricción de la libertad. En cuanto a la competencia de la nueva jurisdicción se debe decir que se refiere a todos los responsables, es decir, a todos los miembros de la guerrilla y del Estado, pero señalando la referencia a «los casos más graves y representativos» y a los delitos «más graves y representativos». Con esto se cumple una responsabilidad del Estado de derecho que es el ejercicio del ius puniendi, el derecho o facultad del Estado para castigar.

Los opositores del proceso de paz consideran que si los guerrilleros son juzgados en el marco de la nueva Jurisdicción Especial para la Paz, estaremos ante el proceso de legalizar la capitulación ante las FARC:

El acuerdo prevé que el Tribunal aplicará un régimen de sanciones, que no reflejan los estándares aceptados sobre el castigo adecuado frente a abusos graves, y hacen que sea prácticamente imposible que Colombia cumpla con sus obligaciones vinculantes conforme al derecho internacional de asegurar justicia por delitos de lesa humanidad y crímenes de guerra (HRW, 2015, septiembre 21).

Esta crítica es importante y debe ser tenida en cuenta, pero la aseveración de su vocero José Miguel Vivanco (Gómez, 2015, diciembre 22), según la cual el acuerdo es un pacto de impunidad — un intercambio de impunidades entre el Estado y la guerrilla- debe ser cuestionada con razones jurídicas y 
políticas. Pero antes de terminar se deben relacionar los resultados obtenidos hasta ahora con los elementos filosóficos de la reflexión sobre la justicia, la guerra y la paz.

En un ámbito estrictamente jurídico tenemos aquí la articulación de una concepción de justicia transicional en la que se responde a los problemas y tensiones que plantearon autores clásicos como De Vattel (1916), Grocio (1925) y Hobbes (1994) cuando pensaron en alternativas para salir de la guerra. El primero consideró que la guerra es un hecho ineluctable entre los Estados y un instrumento de la vida política, pero insistió en la necesidad de actuar con moderación en la guerra y en las negociaciones de paz para poder alcanzar la paz civil. De otro lado, Grocio consideraba que era absolutamente necesario para que una sociedad pudiera alcanzar la paz, un cierto sacrificio de la justicia, es decir, no era viable en el ámbito de la justicia penal tratar la criminalidad masiva con una persecución penal masiva e individualizada. Para Hobbes la salida de la situación insoportable de la guerra de todos contra todos consistió en el establecimiento de un sistema de leyes coactivas que debía ocuparse de una coordinación de las acciones libre de violencia y que sirviera para garantizar una coexistencia pacífica de los hombres, la justicia no era otra cosa que la totalidad de esas leyes.

Estas ideas tienen validez para nosotros hoy. Estas tesis de Grocio y Hobbes encuentran precisamente su aplicación en los componentes de la estructura normativa con los que se está desarrollando el proceso de negociación. En este sentido, los conceptos de priorización y selección de casos, juzgamiento mediante macroprocesos o la renuncia a la persecución penal de casos no seleccionados, expresan de forma clara qué quiere decir en nuestro contexto limitar la justicia para alcanzar la paz.

\section{Conclusión}

No hay incompatibilidad entre los valores de justicia y paz en la medida en que pueda mostrarse que en el Marco Jurídico para la Paz (MJP), en los acuerdos conseguidos en La Habana y en el Nuevo Acuerdo Final (NAF), la verdad está vinculada con cierta forma del reconocimiento público de los actos criminales, con la reparación de las víctimas y con la no repetición de la violencia. Para alcanzar la paz y poder fortalecer la democracia es necesario que los miembros de la sociedad perdonen y estén también dispuestos a la reconciliación (De Greiff, 2006). Muchas personas consideran que es muy 
difícil que en una transición de la guerra a la paz se piense que la justicia y la búsqueda de la paz se puedan ver como procesos paralelos y que se benefician mutuamente. La tendencia normal y mayoritaria es suponer que si los criminales no son procesados y juzgados ellos quedan libres de toda culpa y responsabilidad, y que la justicia no ha sido realizada.

Sin embargo, tanto en el MJP como en el NAF se defiende la tesis de que en este proceso transicional "los casos más graves y representativos» y los delitos «más graves y representativos» serán juzgados bajo las condiciones establecidas en la Jurisdicción Especial para la Paz. Es importante destacar una y otra vez lo que enuncia el Artículo Transitorio 66 de la Constitución «que los instrumentos de justicia transicional serán excepcionales y tendrán como finalidad prevalente facilitar la terminación del conflicto armado interno y el logro de la paz estable y duradera, con garantías de no repetición y de seguridad para todos los colombianos» (Acto Legislativo 01 de 2012).

Se debe entender, entonces, de manera más flexible la tesis penal del retributivismo, según la cual los perpetradores de delitos atroces no queden en la impunidad. Esta solamente se da cuando los criminales quedan libres de toda culpa y responsabilidad, no cuando ellos están sujetos a un sistema alternativo para averiguar quién es el criminal, poder acusarlo públicamente y establecer las responsabilidades. Es claro entonces que una justicia transicional así concebida, orientada a la búsqueda de la verdad y, por tanto, de la responsabilidad de los autores de las atrocidades cometidas y al resarcimiento de las víctimas no equivale para nada a la impunidad, la cual resultaría de una amnistía política absoluta e incondicional.

En la justicia transicional en general, y en la forma como esta se está desarrollando en Colombia, se da una profunda tensión entre los valores de la justicia y la paz, entre derecho y política, entre una justicia retributiva que mira hacia el pasado y una justicia restaurativa que mira hacia el futuro. El enfoque retributivo de justicia afirma que el que comete un crimen debe ser tratado como un criminal y excluido por un tiempo prudencial de la libertad y comunicación con los otros hombres, de acuerdo con la gravedad de la falta cometida. La justicia transicional considera, por el contrario, que es necesario para poder alcanzar la paz un cierto sacrificio de la justicia, es decir, no es viable en el ámbito de la justicia penal tratar la criminalidad masiva con una persecución penal masiva e individualizada, como se supone en un enfoque maximalista. 


\section{Referencias bibliográficas}

1. Ambos, Kai. (2013). ¿Castigo sin soberano? lus puniendi y función del derecho penal internacional. Bogotá, D. C.: Universidad Externado de Colombia.

2. Biral, Alessandro. (2002). Hobbes: la sociedad sin gobierno. En: Duso, Giuseppe. (ed.). El contrato social en la filosofía política moderna (pp. 51-108). Valencia: Res Publica.

3. Colombia. Congreso de la República. Acto Legislativo 01. (31 de julio de 2012). Por medio del cual se establecen instrumentos jurídicos de justicia transicional en el marco del artículo 22 de la Constitución Política y se dictan otras disposiciones. Recuperado de http:/www.alcaldiabogota.gov.co/sisjur/normas/ Norma1.jsp? $\mathrm{i}=48679$

4. Colombia. Corte Constitucional. Sentencia C-579. (2013). Instrumentos jurídicos de justicia transicional-Marco Jurídico para la Paz. Recuperado de http:// www.corteconstitucional.gov.co/relatoria/2013/C-579-13.htm

5. Comité Internacional de la Cruz Roja. (1977). Protocolo II adicional a los Convenios de Ginebra de 1949 relativo a la protección de las víctimas de los conflictos armados sin carácter internacional. Recuperado de https://www.icrc.org/ spa/resources/documents/misc/protocolo-ii.htm

6. Crocker, David A. (2000). Retribution and Reconciliation. Philosophy and Public Policy, 20 (1), pp. 1-6.

7. De Greiff, Pablo (ed.). (2006). Justice and Reparations. En: The Handbook of Reparations (pp. 460-470). Oxford: Oxford University.

8. De Vattel, Emmerich. (1916). The Law of Nations of the Principles of Natural Law. Washington, D. C.: Carnegie Institution.

9. Duff, Antony. (2015). Sobre el castigo. Por una justicia penal que hable el lenguaje de la comunidad. Buenos Aires: Siglo xxı.

10. El Tiempo. (2016, septiembre 28). Farc tienen 5.765 miembros en sus filas. Recuperado de http://www.eltiempo.com/politica/proceso-de-paz/numero-deguerrilleros-de-las-farc-en-sus-filas/16713660

11. Elster, Jon. (2006). Retribution and Reparation in the Transition to Democracy. Cambridge: Cambridge University.

12. Gómez Maseri, Sergio. (2015, septiembre 22). Human Rights Watch critica acuerdo de justicia de Gobierno y Farc. El tiempo. Recuperado de http://www. eltiempo.com/mundo/ee-uu-y-canada/proceso-de-paz-hrw-critica-acuerdo-de-justiciadel-proceso-de-paz-en-cuba/16464887

13. Grocio, Hugo. (1925). De iure belli ac pacis. (On the Law of War and Peace). Oxford: Clarendom.

14. Habermas, Jürgen. (1998). Facticidad y validez. Madrid: Trotta.

15. Hampton, Jean. (2007). The Intrisic Worth of Persons. Contractarianism in Moral and Political Philosophy. Cambridge: Cambridge University. 
16. Hegel, G.W.F. (1993). Fundamentos de la Filosofía del Derecho. Madrid: Libertarias Prodhufi.

17. Hobbes, Thomas. (1994). Leviatán o la materia, forma y poder de una república eclesiástica y civil. México, D. F.: Fondo de Cultura Económica.

18. Human Rights Watch (HRW). (2015, septiembre 21). Análisis de Human Rights Watch sobre el "Acuerdo sobre las Víctimas del Conflicto» alcanzado por el gobierno de Colombia y las FARC. Recuperado de https://www.hrw.org/es/news/2015/12/21/ analisis-de-human-rights-watch-sobre-el-acuerdo-sobre-las-victimas-del-conflicto

19. Jakobs, Günther. (2007). La pena estatal: significado y finalidad. En: Montealegre, Eduardo (coord.). Derecho penal y sociedad. Tomo II. Estudios sobre la obra de Günther Jakobs y Claus Roxin, y sobre las estructuras modernas de la imputación. Bogotá, D. C.: Universidad Externado de Colombia.

20. Jaspers, Karl. (2011). El problema de la culpa. Barcelona: Paidós.

21. Kant. Immanuel. (1986). Teoría y práctica. Madrid: Tecnos.

22. Kant, Immanuel. (1989). La metafísica de las costumbres. Madrid: Tecnos.

23. Primoratz, Igor. (1989). Justifying Legal Punishment. New Jersey: Humanities.

24. Pufendorf, Samuel. (2002). De los deberes del hombre y del ciudadano según la ley natural en dos libros. Madrid: Centro de Estudios Políticos y Constitucionales.

25. Rawls, John. (1978). Teoría de la justicia. Madrid: Fondo de Cultura Económica.

26. Weber, Max. (2002). Economía y sociedad. Esbozo de sociología comprensiva. Madrid: España. 